\title{
Ten Ethical Issues in Exploring Our Solar Ghetto \\ Peters $\mathrm{T}^{*}$
}

Center for Theology and the Natural Sciences, Berkeley, California, USA

"Corresponding author: Peters T, Center for Theology and the Natural Sciences, Berkeley, California, USA, Tel: +1 510 524.5264; E-mail: tedfpeters@gmail.com

Received date: Feb 26, 2016; Accepted date: March 14, 2016; Published date: March 18, 2016

Copyright: $\odot 2016$ Peters T. This is an open-access article distributed under the terms of the Creative Commons Attribution License, which permits unrestricted use, distribution, and reproduction in any medium, provided the original author and source are credited.

\begin{abstract}
The field of Astroethics addresses moral and societal issues arising out of speculation regarding terrestrial contact with extraterrestrial life in both its intelligent and non-intelligent forms. This article tackles ten issues associated with space exploration within the solar system, wherein it is expected that only microbial life, if any life, is likely to be discovered. The ten issues are these: 1) Planetary protection; 2) Does life have intrinsic value? 3) Should space explorers invoke the Precautionary Principle? 4) Should we clean up our space junk? 5) What should we do about Satellite Surveillance? 6) Should we weaponize space? 7) Should scientific research take priority over commercial space ventures? 8) Should we terraform Mars? 9) Should we colonize Mars? 10) Should we prepare for bombardment of Earth by asteroids?
\end{abstract}

Keywords: Ethics; Astroethics; Space ethics; Planetary protection; Space debris; Satellite surveillance; Terraforming Mars; Colonizing Mars; Precautionary principle

\section{Introduction}

Astrobiology needs astroethics. Astrobiologists, according to SETI's Margaret Race, must "acknowledge that science and technology are embedded inseparably in societal and cultural contexts" [1]. We also need astroethics because both science and science fiction dealing with space travel flood our public consciousness. What happens off-Earth cannot help but become a matter of grave concern for all of us who live on Earth. Without doubt terrestrial Homo sapiens are going to have an impact on extraterrestrial places and, quite likely, extraterrestrial realities will impact our life here at home. It's time for space ethics or astroethics to inform, guide, and direct terrestrial science, technology, and perhaps even commerce when we humans go to space.

"The job of ethics is to evaluate issues of right and wrong, or good and bad, directing our focus to normative questions of value," contends space philosopher Cleland and Wilson [2]. To date, curiously, normative questions have seldom been raised to engage the flood of issues arising out of our increased capacity for becoming present in offEarth locations. To date, the only concern to be given thorough ethical and public policy attention has been planetary protection that is, protecting Earth from alien contamination while giving some consideration toward protecting off-Earth habitats from terrestrial contamination. Beyond planetary protection, the field of astroethics is fertile, but still waiting for plowing.

The field of astroethics must be divided into two sub-fields, ethics dealing with extraterrestrial intelligent life (ETIL) and ethics dealing with extraterrestrial non-intelligent life (ETNL). ETNL is usually referred to as microbial life, occasionally even "stupid" life. If we make contact with the ETIL, it will most likely be associated with extrasolar planets in the habitable zone. Intelligent life, if it exists, will be found in the larger Milky Way metropolis [3]. If we make contact with the microbial life, it will most likely be within our own solar ghetto on Mars or a moon of Saturn or a similar location. In this article, we will restrict our attention to the search for microbial life within our solar ghetto. In other articles [4-6], I take up astroethics directed toward contact with ETIL elsewhere in the Milky Way.

Even though the field of 1) Planetary protection has already been plowed, we will review briefly what has been said ethically about it. Then, we will turn to a continuing list of potentially important issues to which only minimal attention has been given: 2) Does life have intrinsic value? 3) Should space explorers invoke the Precautionary Principle? 4) Should we clean up our space junk? 5) What should we do about Satellite Surveillance? 6) Should we weaponize space? 7) Should scientific research take priority over making a buck? 8) Should we terraform Mars? 9) Should we colonize Mars? 10) Should we prepare for bombardment of Earth by asteroids?

To orient ourselves toward formulating and then addressing ethical issues, let me allude to some preliminary contributions already offered by SETI exobiologist Margaret Race and Methodist bioethicist Richard Randolph. Race and Randolph have proposed four principles for developing an ethical scheme appropriate to the discovery of nonintelligent life in our solar system: 1) cause no harm to Earth, its life, or its diverse ecosystems; 2) respect the extraterrestrial ecosystem and do not substantively or irreparably alter it (or its evolutionary trajectory); 3) follow proper scientific procedures with honesty and integrity during all phases of exploration; and 4) ensure international participation by all interested parties [7]. This opening moral salvo makes a commitment to planetary protection; to treating off-Earth ecosystems has having intrinsic value; to demanding scientific integrity; and to emphasizing that all peoples on Earth belong to a single community of moral deliberation. In this spirit I will turn to ten issues arising from the prospect that our space explorers will find the gold: non-intelligent yet beloved life elsewhere in our universe.

\section{Planetary Protection}

The first on our list of ethical issues arising from the search for ETNL is planetary protection (PP). PP raises a concern to protect ecosystems from contamination by alien life forms that may be destructive. The risk of contamination goes in two directions, forward and backward. The possibility of forward contamination alerts us to 
the risk of disturbing an already existing ecosphere; the introduction of Earth's microbes carried by our spacecraft or equipment could be deleterious to an existing habitable environment. Back contamination would occur if a returning spacecraft brings home rocks or soil samples that contain life forms not easily integrated into our terrestrial habitat. A quarantine program will be required to determine the safety of newly introduced ETNL.

Article IX of the 1967 UN Outer Space Treaty states that “...parties to the Treaty shall pursue studies of outer space including the Moon and other celestial bodies, and conduct exploration of them so as to avoid their harmful contamination and also adverse changes in the environment of the Earth resulting from the introduction of extraterrestrial matter and, where necessary, shall adopt appropriate measures for this purpose..." This PP principle has been guiding us since 1967.

In practice, prevention of backward contamination trumps protection against forward contamination. NASA scientists responsible for planetary protection, Conley and John, recommend that planetary protection be incorporated from the earliest stages of mission planning and development to ensure proper implementation. Although forward contamination is a matter of concern, some forward contamination is permissible. What is not permissible is backward contamination. Preventing harmful contamination of the Earth must be of the "highest priority" for all missions [8].

Our terrestrial imagination is expanding in light of growing knowledge of space. Increasingly, we view our planet Earth within a cosmic horizon. In the words of Wickramsinghe, our ethics must "make the switch from an Earth - centered to a cosmic-centered life imperative" [9]. With the cosmic horizon in mind, theological ethicist John Hart offers an augment to planetary protection by introducing the moral category: cosmic commons. If we understand our solar system or even our universe as a commons, we will think of a "shared space or place that provides both an abiotic (non-living) home and habitat for the biotic community (the community of all life), and the natural goods (resources) needed for biotic sustenance and well-being" [10]. Although planetary protectionists to date have not invoked the category of the cosmic commons, it may already be at work at the level of presupposition. Mars along with numerous off - Earth sites belong to this commons and deserve fitting protection just as Earth does. NASA's planetary protection officer, Conley, could not be clearer: "If you want to study life elsewhere, you have to make sure not to bring Earth materials along" [11].

\section{Does Life have Intrinsic Value?}

Does life have intrinsic value? Or, does the value of living organisms depend on the usefulness they have for us? Is value inherent or instrumental? Do we terrestrial Homo sapiens have a responsibility toward extraterrestrial life based upon that life's intrinsic worth or based upon its usefulness to us? Almost no one to date has risen up to defend a brute instrumentalism, a crass exploitation of extraterrestrial life for terrestrial profit. What space explorers want to know is this: if we find life, must we respect and protect it?

Will the life our space explorers find be alien? Will it be the result of a second genesis? Or, will it be related to life on Earth? Some panspermia theorists contend that the essential biochemical requirements of life exist in very large quantities within the dense interstellar clouds of gas. This cloud material has infected the Earth with the same pre-biotic or even biotic chemistry found everywhere in the universe. According to Wickramasinghe and Tokoro, among others, meeting alien life is to meet our own family. Astrobiologists should be working with the panspermia paradigm, they insist [12]. With growing evidence to support panspermia and the probability that life is a cosmic phenomenon, terrestrial societal attitudes might change. The ethical implication is this: if we attribute intrinsic value to life on Earth then this should apply directly to the way we value life off-Earth.

Because of the obvious carry over to space ethics from environmental ethics, we might remind ourselves of the concerns voiced early in the deep ecology movement. Norwegian eco-sophist Arne gave us the term deep ecology in 1973, arguing for an exhaustively systemic view of nature and for treating both human and nonhuman life alike as having "intrinsic value" [13]. This metaphysical commitment would imply ethically that we treat all of living nature as sacred. If we sacrilize the entire living world in nature, deep ecologists presume, then we human beings would treat our biosphere with reverence, respect, and responsibility. Might we borrow this principle for off-Earth biospheres, treating newly discovered life forms as having intrinsic rather than instrumental value?

Yes, would be the answer offered by environmental philosopher Holmes, who argues against the instrumental approach on the grounds that non-human nature preceded human beings who value things. "Humans on Earth are latecomers, and it seems astronomically arrogant for such late products to say that the system is only of instrumental value, or that not until humans appear to do their valuing does value appear in the universe" [14]. Valuing in general is grounded in nature, not in human preference, holds Holmes. This opens the door for treating off - Earth ecospheres as having intrinsic worth and integrity.

However, today's descendants of sixteenth century Reformation Protestants find it difficult to treat anything created as sacred in it. God the Creator is sacred, to be sure; but the world of nature-whether living or non - living belongs in the category of creature. Human dignity is called for, to be sure; and so is responsible stewardship called for. But not an intrinsic sacredness spread around to all living things. What is created cannot bear in itself an ontological sacredness. Nevertheless we might ask: could a creature be sacred if God deems it sacred? Might we appeal to intrinsic value if God imputes intrinsic value?

Richard Randolph, mentioned earlier, would answer in the affirmative. He affirms the intrinsic value of life by appeal to God. "From a Christian point of view, God's preferential option for life means that all of life has intrinsic value. By this I mean that all living organisms, as well as their ecosystems, are entitled to a basic, underlying level of respect and, even reverence by humans. Every living organism is good in and of itself, regardless of the instrumental value it may have for humans [15]. We human beings on Earth should express this intrinsic worth of extraterrestrial life by behaving as servant / stewards, supporting both living organisms and their respective habitats wherever they may be found. God's preferential option for life grounds the claim that all of life has intrinsic worth and that God intended for extraterrestrial life to flourish and be selfdeterminant [15]. In Naess and Holmes, the intrinsic value of the natural world derives from our treating nature as sacred. In Randolph, in contrast, the intrinsic value of the natural world derives from the respect God shows for it. The resulting sense of moral responsibility is the same in both cases. 
Page 3 of 8

Still we must ask: does intrinsic value apply to all life generally or only to selected living organisms? Might we discriminate between some life forms and other life forms, granting more worth in some cases and less in other cases? If so, what will be our criterion for selection?

A flat attribution of intrinsic value to all of nature or, within this all of life, is difficult to ground without appeal to God, who transcends nature. First, life does not treat itself with intrinsic value. Predation, for example, pervades the domain of living things. Life eats life. Some life dies so that other living things may live. Thus, if we human beings are going to protect life on the grounds of its intrinsic value, we do so for reasons other than imitating life itself. Second, we daily treat some living organisms instrumentally. Everything we eat we kill, except for salt. Plants and sometimes animals are sacrificed for our own survival or pleasure. We do this without thinking ethically. Therefore, if we are to impute intrinsic value to living entities in outer space, we may need to discriminate; and we may need to provide a reason for this discrimination.

Notre Dame University Bioethicist Deane-Drummond contends that the concept of intrinsic value does not preclude discriminating between greater or lesser worth. "It is possible to hold to the notion of intrinsic value, while also being able to discriminate between different forms of life and non-life in terms of their worth" [16]. Or, to say it another way, even if we impute intrinsic value to all living things, within this wide category we may identify some living things to be of greater value or worth. But, we ask: how do we decide? Without appealing to instrumental criteria for discriminating between greater or lesser worth, we should look for criteria within the scope of intrinsic value. One candidate might be sentience. Complex life forms are sentient in a way that we humans are sentient; whereas more simple life forms lack this attribute. Could sentience provide the criterion of discrimination?

Persson, bioethicist at Lund University in Sweden, appeals to sentience within the larger category of life. "According to sentientism, one has to be sentient to have moral status whether terrestrial or extraterrestrial and whether biological or non-biological [such as post biological].... The most plausible theory for moral standing seems to be sentientism that connects directly to the basic idea behind modern ethics: that ethics is about dealing with situations where one's own actions affect others in a way that matters to them.... "If we accept sentientism, microbial life and plants do not have moral status, but there are reasons for protecting someone or something other than being a moral object" [17]. Complex or sentient life has greater moral worth than simple or primitive life, according to this scheme. Will this work? No.

Sentience will not work as a general ethical category, except for vegetarians. Here on Earth we have already committed ourselves to eating meat. Meat-eating requires the death of sentient creatures. We discriminate between pets, which we do not eat, from stock, which we do eat. Vegetarians object to this practice on moral grounds, on the grounds that we have a responsibility to all sentient creatures. If we are to export to extraterrestrial realms a categorical respect for all sentient organisms, then for the sake of consistency we would need to adopt vegetarianism back at home. A consistent ethic based upon sentience would require vegetarianism on Earth as well as on all space expeditions.

Sentience will not help for another reason. To date, those contributing to this discussion have drawn on ethical precedents set by environmentalists and eco-ethicists. This ethical posture is oriented holistically toward entire ecosystems, toward protecting entire habitats with their resident living creatures regardless of level of sentience or intelligence. This holistic approach seems intuitively relevant to what we might discover on Mars or a moon orbiting Saturn. Once engaged, we would not discriminate between one species on behalf of another species. Rather, we would assume we are responsible for each entire biosphere with its already established life forms. Entailed in a holistic commitment to an entire ecosystem is an indispensable level of commitment to simple life forms and even to abiotic contributors to this ecosystem.

In sum, we may have to live for a period with a generic respect-forlife's-intrinsic-value principle until we have entered into actual engagement with ETNL or ETIL. At that point we will re-articulate the quandary and re-formulate our responsibility. By no means is this a form of kicking the ethical can down the road. Rather, we are simply marking specific areas where we will need to respond to actual rather than hypothetical situations.

\section{Should Space Explorers Invoke the Precautionary Principle?}

In order to follow my moral advice in the previous section, we might find the Precautionary Principle worth adopting. Earth's ecologists are already used to debating and commending the Precautionary Principle. Might astroethicists borrow it?

The so-called Wingspread Definition of the Precautionary Principle was formulated at the 1992 United Nations Conference on Environment and Development: "When an activity raises threats of harm to human health or the environment, precautionary measures should be taken even if some cause and effect relationships are not fully established scientifically. In this context the proponent of the process or product, rather than the public, should bear the burden of proof [18]. When space scientists and ethicists met at Princeton for a COSPAR workshop in 2010, they embraced a variant formulation: "we define the precautionary principle as an axiom which calls for further investigation in cases of uncertainty before interference that is likely to be harmful to Earth and other extraterrestrial bodies, including life, ecosystems, and biotic and abiotic environments" [19]. For the time being, space explorers from Earth may wish to treat newly discovered life forms as if they possess intrinsic value, at least until further ethical deliberation takes place.

Employment of the Precautionary Principle for space exploration provides the kind of middle axiom that connects the larger value of life with practical policies that facilitate off Earth activities.

\section{Should We Clean Up Our Space Junk?}

Currently, about 22,000 large pieces of space junk in the form of dead satellite parts are orbiting Earth. We have turned our upper atmosphere into a trash dump. Do we want to pollute extraterrestrial space just as we have befouled our terrestrial nest?

Over the last half century we earthlings have shot up into space approximately 20,000 metric tons of material. 4500 metric tons remain in orbit, broken into countless chunks of junk. Of the 4800 satellites placed in orbit, half of these, 2400 , are still present. But, of these 2400 satellites, only 600 or so are still active. The inactive satellites and other rocket debris sail silently like a never - ceasing stream of unaimed bullets just waiting for a target to get into their way [20]. 
The problem with our orbiting landfill is not merely that it is ugly. It is also dangerous. It risks danger to future space flights and future satellites. Jacques, astroethicist for the French Centre Nationale d'Etudes Spatiales (CNES), warns us: "there are now 22,000 human made objects larger than 10 centimeters across in orbit and half a million larger than $1 \mathrm{~cm}$ and all pose a grave risk to space missions.... Even if space agencies never launched another rocket, the cloud of debris will continue to grow as pieces of space junk crash into one another" [21]. As space junk crashes, each piece fragments and multiplies the number of dangerous micrometeorite material that risks damage to future space vehicles we send up. Some space scientists fear a runaway chain reaction called the Kessler syndrome that pulverizes everything in orbit, including functioning satellites. This would establish a band of untraversable danger, a no - man's land in space. Here is the warning: for safety's sake, stay out of the space dump.

To date, no one has been held responsible for space junk. Those who make profits or who otherwise gain from sending this material into space are not required to recycle or dispose of their waste. Space waste accumulates, but nobody is required to pay for cleaning it up. Nations or corporations treat the Greater Earth or cosmic commons as their ashtray, as a public trash dump. Follow the money.

If we define Greater Earth as a part of the cosmic commons, then we find ourselves already beset with a classic moral problem: those with power and influence utilize common space for their own profit while the population as a whole absorbs the cost of deterioration or degradation of what is publically shared. If and when our planetary society consolidates its diversity into a single community of moral deliberation, then responsibility will need to be parsed and parceled according to a renewed principle of justice.

The European Space Agency has set up a Space Debris Office to coordinate research activities in all major debris disciplines, including measurements, modeling, protection, and mitigation, and coordinates such activities with the national research efforts of space agencies in Italy, the United Kingdom, France and Germany. Together with ESA, these national agencies form the European Network of Competences on Space Debris.

The Japan Aerospace Exploration Agency (JAXA) is testing to see if a tethering technique might begin the process of debris-gathering. The tether consists of a long conductive wire attached to a junk chunk which, by implementing an electrodynamics drag, would pull the debris into the atmosphere where it would burn up. The Space Tethered Autonomous Robotic Satellite - 2 (STARS - 2) is testing the idea and, if it works, then it could be attached to future missions aimed at capturing existing debris [22].

\section{What Should We Do About Satellite Surveillance?}

Reconnaissance satellites or spy satellites have been deployed over sixty years for purposes of military or intelligence applications. The telescopes on board are pointed toward Earth, not toward the stars. Mission tasks include high resolution photography; measurement and signature intelligence; communications eavesdropping; covert communications; monitoring of nuclear test ban compliance; and detection of missile launches. With the improvements in technology, today's spy satellites have a resolution capacity down to objects as small as ten centimeters. Surveillance satellites also provide us with efficient communications, weather reporting, Google maps, and many more public services.
Spying is international, not just national. The Echelon spy network coordinates satellite snooping by the governments of the United Kingdom, the United States, Canada, Australia, and New Zealand. The Echelon network spies, sorts, decrypts, archives, and processes three million telephone calls transmitted by satellite every minute.

Remote sensing and communication technologies were developed before any legal structure was put in place to govern their developments. The United States government sells pictures taken by satellites; but it keeps certain subjects from public review. Sensitive facilities such as military installations are restricted, as are remote pictures taken over Israel. Similarly, private companies use satellites for remote sensing and sell their pictures.

"Can a State gather information about the natural riches and resources of another sovereign State without having obtained the latter's prior agreement?" asks Jacques. "Is it not up to the remote sensing State to ask for the prior permission of the State whose territory is being observed?" [21]. This sounds like a reasonable ethical question. Yet, it presupposes the present situation of sovereign nation states, a political system that may have made sense prior to the current thrust toward economic and technological globalization. Satellite surveillance and communication services, right along with other space activities, are playing into an emerging planetary consciousness.

Protecting national boundaries from foreign intelligence or even public transparency may soon be an artifact of history, an era we remember but no longer live in. Perhaps the way forward is to support an ethic of maximal information without discrimination. Rather than attempt to police information gathered from remote sensing, it would be healthier and easier to prevent such information from deleterious usage.

\section{Should We Weaponize Space?}

"Star Wars" became the nickname for U.S. President Ronald Reagan's 1983 proposal for the Strategic Defense Initiative (SDI). Reagan had inherited the cold war strategy of "Mutual Assured Destruction" (MAD), the policy of detente that had kept the peace between the United States and the Soviet Union since World War Two. Reagan asked his scientists to help him create SDI, which would include among other things space-based weapons. Specifically, these space-based weapons would rely upon lasers aimed at shooting down Soviet Intercontinental Ballistic Missiles (ICBMs).

Reagan's Strategic Defense Initiative Organization (SDIO) worked with an earlier idea developed by physicist Edward Teller for an X-Ray laser. Then, SDIO funded newer ideas. Beginning in 1985, designs and tests were planned for innovative forms of laser technology. The U.S. Air Force tested a deuterium fluoride laser, also known as the MidInfrared Advanced Chemical Laser. Later the Air Force tried shooting an old satellite with a Tactical High Energy Laser; and the U.S. Navy shot at drones with similar laser designs. The best these experiments could report was "mixed" success, just enough success to keep funding flowing.

Today, eyes on militarizing space are looking up. "For modern warfare, space has become the ultimate high ground, with the U.S. as the undisputed king of the hill," writes Billings [23]. China and Russia are both developing capabilities to sabotage crucial U.S. military satellites [23]. Laser technology has advanced, so that satellites will begin to use lasers to disable other satellites. One can only imagine a skirmish that could lead to Star Wars or, more precisely, Satellite Wars. 
Page 5 of 8

This scenario is important; because the 1967 United Nations Outer Space Treaty emphasizes that celestial locations could be used "exclusively for peaceful purposes." The treaty explicitly prohibited the "placing in orbit around the Earth any objects carrying nuclear weapons or any other kinds of weapons of mass destruction." A light saber battle between satellites was not explicitly prohibited. Any regulation of military equipment in space is today the responsibility of bilateral and multilateral agreements, not the United Nations. No global community of moral deliberation exists, at least not yet.

\section{Scientific Research vs. Making a Buck}

Economic and political motivations for gaining dominance in space may increase over the next decades. The telecommunications industry is already accustomed to the cost effective use of satellites. We are on the brink of an era of space tourism, with the first trips to sub orbit and low orbit vacations in the planning stages. Visits to the moon will most likely follow. Establishing research laboratories on the moon and Mars are being envisioned. Might it be prudent to ready ourselves for an El Dorado type of gold rush to the new extraterrestrial world? If so, should we try to put policies and policing mechanisms in place in advance?

Up until this point we have thought of outer space as a sandbox for Earth's scientists to play in. Governments have found the money to fund modest exploratory adventures; and scientists have organized to conduct experiments which have yielded an abundant harvest of new knowledge about our cosmos. Frequently, scientific goals have been mixed with military goals, because leaders in the military have been willing to share their budgets for scientific purposes. Scientific experiments do very little damage, if any. Somewhere on the Moon is a golf ball left by visiting astronauts. Landing on Mars or on Titan has not infected or contaminated anybody's ecosystem, as far as we know. NASA decontaminated its first Mars lander, but more recently NASA has saved the money spent for decontamination under the assumption that a little contamination of Mars doesn't matter. The impact on our solar system by scientific activity is benign.

This situation is about to change. The private sector is now ogling space for profit. What about space tourism? Simply flying a few wealthy passengers high enough to experience weightlessness is not likely to provoke anyone's moral ire. But, what about tour busses roaming the surface of the Moon? Busses will leave tire tracks. Perhaps trash, no doubt tourists will want to visit that golf ball as well as historical sites where astronauts first landed. Will the crowds of visitors damage those sites? Are those sites sacred? Protectable? Who will decide and what will be the criteria by which they decide?

The market does not always react the way the marketers predict. Low cost and frequent flights to sub orbit heights might actually encourage increased participation by scientists. These scientists will want to do research on the ignorosphere. The ignorosphere is a level just above balloon traffic but too low for satellites. Scientific researchers might buy tickets with the tourists and then look out the windows [24].

\section{Terraforming Mars}

Should we terraform Mars? Or, any other planet or moon, for that matter? Will we Earthlings rest content until we see the golden arches of McDonalds on the red planet?

One person who would resist McDonalds' golden arches on Mars is Woodruff. "I will argue for an extension and adaptation of a rigorous environmental ethics stance that has been proposed for Earth. On this scheme, planets have intrinsic value. Such a planetocentric ethics treats all planets somewhat as we treat designated wilderness areas on Earth that is, with a 'hands off' approach unless other treatment is strictly justified for scientific or other needs" [25]. Note that Woodruff argues for 'hands off' regardless of whether there is or is not life on Mars.

Our Mars Man is Christopher McKay, a space scientist at NASA's Ames Research Center. According to McKay, we work with the assumption that Mars is lifeless. At least it is lifeless today. The red planet may have been home to life in the past; but Mars must have lost its atmosphere and its ability to sustain life for reasons yet unknown. Its thin atmosphere is replete with carbon dioxide, but not oxygen. Let us speculate: suppose we would transplant living organisms from Earth that take in carbon dioxide and expel oxygen into the atmosphere? Then, when enough oxygen suffuses the atmosphere, we could introduce oxygen inhaling organisms that expel greenhouse gases. These greenhouse gases would warm up Mars, and life would thrive. A self-regenerating ecosystem could run on its own. In less than a century, estimates McKay, we could establish a biosphere that would last ten to a hundred million years.

McKay calls this terraforming project "planetary ecosynthesis." This proposal for planetary ecosynthesis raises a number of ethical concerns. Immediately, one might ask: should we do it? To what do we appeal ethically to answer this question?

McKay starts with a simple axiom: life is better than non-life. I suggest that the long - term goal for astrobiology and society is to enhance the richness and diversity of life in the Universe [26]. Virtually no one who mulls over the question of life's intrinsic value would challenge McKay's starting point. But, we ask: what comes next?

On Earth the principle that life is better than non - life has influenced our decisions and policies to preserve life. We preserve species from distinction. We preserve habitats to encourage certain species to proliferate. In short, we attempt to prevent certain forms of life from dying out.

This would not apply to Mars, however. If we assume that Mars is currently lifeless, then we would not find ourselves preserving existing life. Rather, the question is: should we seed life on Mars? If life is better than non-life, says McKay, then the moral answer should be in the affirmative. Transferring terrestrial life forms to Mars would be better than leaving Mars lifeless.

Curiously, McKay appeals to both intrinsic value and instrumental or utilitiarian value when justifying planetary ecosynthesis. First, the intrinsic argument, because life has intrinsic value, Mars with life would be ethically of greater worth than a lifeless Mars, even if it is transplanted life. Second, the instrumental argument, because we on Earth would learn so much from the Mars project about sustaining a biosphere, we could apply what we learn on Mars to sustaining Earth's biosphere in the face of our imminent ecological challenges. Both utilitarian and intrinsic worth arguments support the notion of planetary ecosynthesis [27].

How might such an argument sit with a theologian? With a Buddhist theologian? Cho, Associate Professor of Buddhist Studies at Georgetwon University, offers a Buddhist interpretation. "A Buddhist would apply neither an intrinsic nor instrumental value of life or nature to the question of terraforming Mars. The idea of an intrinsic value would go against the principle of emptiness. Instrumental value, on the other hand, would be problematic because one could not ensure 
Page 6 of 8

that the instrumental objectives had the proper motivations.... There is no intrinsic worth to nature but neither is there intrinsic worth to human beings.... There is no option between them, so you have to transcend that framework all together" [28]. From a Buddhist perspective, neither an appeal to the intrinsic value of life nor an appeal to life's utilitarian value to human beings provides ethical guidance for the terraforming question.

Another issue appears on our moral radar screen, namely, the risk that we terrestrials will make a mess out of Mars. We have already spoiled one planet. Will we spoil others? Theologian Crysdale recommends that we incorporate this risk into our ethical vision. "We need to think of ourselves as living within an ethic of risk, not an ethic of control. I say this in direct reference to the actions we take in terraforming or colonizing or exploring other planets. My caution is to point out that the conditions of possibility that we establish in the hopes of one outcome may at the same time establish conditions under which totally unforeseen schemes of recurrence become established" [29]. Dr. Crysdale has wisely asked us to consider human nature that is, human sinfulness when making plans. No ethical justification could suffice without acknowledgement of who we are as humans. Nevertheless, anticipating the unforeseen damage we humans are capable of is a principle one must incorporate into any such project, regardless of whether it is justified by appeal to an intrinsic or utilitarian ground.

Should we terraform Mars or any other celestial body within our solar ghetto? On the one hand, McKay's argument that life is better than non - life provides a sound point of departure. On the other hand, transplanting terrestrial life to an extraterrestrial location looks a great deal like colonizing. As we bring the history of terrestrial colonization to mind, we cannot avoid recalling the imperialism and greed that motivated colonization and the devastating impact of exploitation and genocide on the lands colonized. The Crysdale incorporation of risk based upon what we know from history about human nature gives one pause.

Our pause cannot last too long. The Mars Society is already making plans to colonize the red planet.

\section{Colonizing Mars}

Colonize Mars? Yes, and more places in the solar system. "Humansto-mars" is the direction Zubrin is leading his followers in the Mars Society. His "Mars Direct" colonization plan "advocates a minimalist, live-off-the-land approach to exploring the planet Mars, allowing for maximum results with minimum investment. Using existing launch technology and making use of the Martian atmosphere to generate rocket fuel, extracting water from the Martian soil and eventually using the abundant mineral resources of the Red Planet for construction purposes, the plan drastically lowers the amount of material which must be launched from Earth to Mars, thus sidestepping the primary stumbling block to space exploration and rapidly accelerating the timetable for human exploration of the solar system" [30]. Money raised from the private sector will support this effort. Mars Society adherents see themselves as rivals to NASA. They are in a space race and plan to beat NASA to the fourth planet.

The Mars Society plans to initiate Mars Direct by sending an "Earth Return Vehicle" or ERV, arriving on the red planet six months following launch from Earth. While on the Mars surface, the ERV will set up and operate nuclear reactors, which will generate the fuel needed for the return trip, 13 months later.
The second Earth-to-Mars launch will take place 26 months after the first, sending two more craft, a second ERV and a habitat module for the astronauts to live in. After a year and a half on the Martian surface, the first crew returns to Earth, leaving behind the habitat, the rovers associated with it and any ongoing experiments conducted there. When they land on Earth six months later, they are greeted to a hero's welcome. From this point on the cycle is repeated, with more and more of Mars opening up to human exploration and habitation. This will be the beginning of a permanent human settlement on the planet Mars.

The Mars One project based in the Netherlands and headed by Bas Lansdorp is making similar plans. As of the summer of 2013 the project planners began their selection of the first crew headed for the Red Planet in 2023. The crew would be given seven years of training in engineering, medicine, agriculture, and astrophysics. This would be a one way trip. Once the astronauts have landed, they would become Martians.

The mood of the Mars Society and the Mars One project is one of promethean expectation. The human race is being called by destiny to go, go, and go. To spread our race throughout the solar system fulfills our inherited evolutionary mandate, to fill every niche with life.

Some Muslims find the prospect of Mars colonization objectionable, especially the risk of self-sacrifice on the part of the first explorers. Because the first wave of travelers from Earth to Mars will know in advance that they will not be returning, the one way trip idea looks like a plan for suicide. To this, Muslim theologians object. In early 2014 the fatwa committee of the General Authority of Islamic Affairs and Endowment in the United Arab Emirates issued the fatwa after determining that "such a one-way journey poses a real risk to life, and that can never be justified in Islam." They continued, "There is a possibility that an individual who travels to planet Mars may not be able to remain alive there, and is more vulnerable to death." Qu'ran 4 / 29: "Do not kill yourselves or one another. Indeed, Allah is to you ever merciful." In sum, suicide is immoral, even on Mars [31].

It would seem to me that we need not think of one way trippers to Mars as necessarily committing suicide. There is a risk of death, to be sure; but there is also the prospect that earthlings might live a normal life span in the atmospheric bubble on Mars' surface. To die of natural causes off-Earth does not necessarily count as suicide, in my judgment.

When the Spanish crown commissioned Christopher Columbus in 1492 to sail west across the Atlantic Ocean, it was hoped he would return with gold and mineral wealth. Europe's race to the new world had begun a race to maximize national power and wealth through exploiting foreign land. Might we see a repeat here? Not exactly, Even if the Mars Society or Mars One are successful at establishing a permanent habitat for earthlings on Mars, it is not clear that this would lead to profits for those back on the third planet who funded their expedition. If profit is to be made, it would not likely occur within the lifetime of those planning the mission. This gargantuan mission will have to rely on the promethean spirit, at least for the near future.

\section{Death from the Sky?}

Back on the third planet, the vast majority of earthlings will still be living here. The very thought that Mars might provide a safe refuge for Homo sapiens once we have polluted our home planet is utterly preposterous, according to anyone who has considered the matter. We had better make our peace with one another and with our own 
biosphere, because Earth will continue to be our home for the foreseeable future. If we Homo sapiens do not get our act together and end up so fouling our habitat that we go extinct, the non-intelligent (might we say "stupid") life in our solar system will not be limited to Titan microbes.

Nevertheless, even with sober ecological policies, Earth will continue to be a dangerous home. The heavens hold plenty of threats. The Sun occasionally launches solar flares, which fry electricity grids by generating intense currents in wires. A solar megastorm in 1859 sparked fires in telegraph offices. If such a flare would reach Earth today, it would knock out satellites and shut down power grids for months or longer. Such an event would incur trillions of dollars in economic damage. Although we rely upon the sun for our daily life, some day it just might kill us.

In addition to solar threats, we need to anticipate the possibility of a large comet or asteroid strike. On February 15, 2013, more than 400 Russian people were injured when an asteroid exploded just above the city of Chelyabinsk. NASA referred to it as a "tiny asteroid" that measured roughly 45 feet across, weighed about 10,000 tons, traveling about $40,000 \mathrm{mph}$. The object vaporized roughly 15 miles above the surface of the Earth, causing a shock wave that triggered the global network of listening devices that was established to detect nuclear test explosions. The force of the explosion measured between 300 and 500 kilotons, equivalent to a modern nuclear bomb [32].

Within hours of the Russian disaster, another asteroid, 2012 DA14 passed between Earth and our geosynchronous satellites. Once or twice every two million years our planet gets smacked by rocks two kilometers or more in diameter, leading to extinctions. It is widely believed among scientists that 65 million years ago an asteroid ten kilometers in diameter hit Earth and triggered the mass extinction of dinosaurs. Can we protect Earth from future asteroid catastrophes? The UN's Science and Technical Subcommittee's Near - Earth Object Working Group and its internal panel, Action Team 14, have been working on the details of an international approach since 2001 to anticipate and thwart such Near Earth Objects (NEOs).

The Action Team identified three primary components of threat mitigation: (a) discovering hazardous asteroids or comets and identifying those objects requiring action; (b) planning a mitigation campaign that includes deflection and / or disruption actions and civil defense activities; and (c) implementing a mitigation campaign, if the threat warrants. The Action Team emphasized the value of finding hazardous NEOs as soon as possible in order to avoid unnecessary delays in NEO threat mitigation missions. Recommendations of the Action Team are meant to: (a) ensure that all nations are aware of potential threats and (b) ensure the design and coordination of mitigation activities among nations that could be affected by an impact and those that might play an active role in any eventual deflection or disruption campaign [33].

Solar flares and asteroid strikes. That's not all. More rare but equally potent would be the blast of radiation from a nearby $\gamma$-ray (gamma ray) burst. A short-hard $\gamma$-ray burst, caused by the violent merger of two black holes or two neutron stars or a combination, provides the most frightening scenario. If one such blast would be directed at Earth from within 200 parsecs away (less than $1 \%$ of the distance across the Milky Way), it would zap Earth with enough high-energy photons to wipe out $30 \%$ of the atmosphere's protective ozone layer for nearly a decade. Such an event - expected once every 300 million years or so would double the amount of ultraviolet light reaching the ground and scorch phytoplankton, which make up the base of the ocean's food web. Astronomers are unable to predict such bursts, so we have no way of knowing whether such a rare event is imminent.

What about long-soft bursts? From a distance of about 2,000 parsecs, 'long-soft' $\gamma$-ray bursts - which result from the collapse of massive stars - could also damage our planet and cause extinctions. Long-soft bursts are rarer than short-hard bursts. In addition, they are easier to spot in advance because they come from larger, brighter stars [34].

How does knowledge of these potential threats from the heavens provoke ethical concerns? Because these damage scenarios lead us to think ahead. We need to plan for our planet's future, and we need to incorporate such possibilities into our planning. With regard to solar flares, fortunately, there are ways to mitigate the damage should it occur: engineers can protect the grid with fail-safes or by turning off the power in the face of an incoming blast. With regard to a comet or asteroid strike, we will be given advanced notice. A diversion strategy could be effective, perhaps by hitting the object while it is yet far away with a nuclear bomb. We have no way to prevent gamma ray bursts from striking our Earth, but we could provide protective shields in sanctuaries for life forms we wish to restart following the event. These matters belong to our ethical quandary. Just how will we respond?

\section{A Single Planetary Community of Moral Deliberation?}

We have been suggesting that the community most appropriate for deliberating over such matters would consist of all the peoples of Earth working together. Race has been making this point based on the principle of inclusivity. "It is important to recognize that current deliberations and decision making are almost exclusively in the realm of scientific and spacefaring elites," observes Race. This suggests that ethicists must be "proactive in expanding the dialogue" so that it becomes planetary in scope. Space ethics must rely on the equivalent of "informed societal consent" [1]. Perhaps the matter of establishing a single planetary community of moral deliberation is even more urgent than Race's push for inclusivity. When confronting scenarios that have a planet-wide impact such as a threatening asteroid, the planet as a whole should become the community of moral deliberation and provide the network to shoulder the responsibility. Planetary plans to meet such threats should be international or supranational. The principle of distributive justice may require that each nation contribute to a coordinated effort in proportion to its capability by providing either technological expertise or funding for such expertise. Planetization is a corollary to the notion of a cosmic commons. Ecoimages such as "green globalization" or "spaceship Earth" connote the circumstances that lead to the concept of a single planetary society. Former US Vice President Al Gore is optimistic. "Fortunately, the awakening of the Global Mind is disrupting established patterns creating exciting new opportunities for emergent centers of influence not controlled by elites... [elites who have set incentives] that reward unsustainable exploitation of limited resources, the destruction of ecosystems crucial to the survival of civilization, unlimited flows of pollution, and the disregard of human and social values" [35]. A longterm global ecoethic or accompanying cosmic astroethic should be the product of a single planetary society that rises above the selfdestructive greed of competing subsidiary economic forces. 
Page 8 of 8

\section{Conclusion}

Despite the fact that the field of astroethics is the new kid in school, already a considerable list of issues appears on its report card. Within our solar ghetto, we must provide ethical deliberation prompted by the prospect that we will be traveling in outer space and that we may discover primal or microbial life, what we affectionately call stupid life, within our solar neighborhood. These prospects elicit an ethical quandary regarding matters such as: planetary protection (including protection of Earth and protection of off-Earth ecospheres); the intrinsic value of extraterrestrial life and of off-Earth ecosystems; what to do about space junk; satellite spying; weaponization of space; the competition between scientific research and economic interests, including space tourism; terraforming Mars; Mars colonization; mitigating the damage done by solar flares, asteroid collisions, and gamma bursts; and such.

These quandaries prompt in us a sense of responsibility. The very knowledge that such challenges may be approaching us in the future is sufficient to prompt in us the question: what should we do? The matter becomes more complex when we ask: just who makes up the community of moral deliberation here? It appears obvious that challenges to the future of all life on Earth actually, all life in the cosmic commons lead to the prospect of planetization. All peoples of Earth in cooperation need to deliberate over what is best for our planet as a whole, and our cosmic commons as a whole. Can the peoples of Earth think of themselves as a single planetary society shouldering responsibility for all biota and even abiotic factors in our solar ghetto?

\section{References}

1. Race MS (2013) "Space Exploration and Searches for Extraterrestrial Life: Decision Making and Societal Issues", in Encountering Life in the Universe, eds., Impey C, Spitz AH, and Stoeger W. University of Arizona Press, Tucson, USA.

2. Cleland CE, Wilson EM (2013) "Lessons from Earth: Toward and Ethics of Astrobiology," in Encountering Life in the Universe, eds., Impey C, Spitz AH, and Stoeger W. University of Arizona Press, Tucson, USA.

3. Strom RG (2015) We are not alone: Extraterrestrial Technological Life in our Galaxy. Astrobiol Outreach 3:144.

4. Peters T (2011) "The implications of the discovery of extra-terrestrial life for religion." Philosophical Transactions of the Royal Society A 369: 644-655.

5. Peters T (2013) "Astroethics: Engaging Extraterrestrial Intelligent LifeForms," in Encountering Life in the Universe, eds., Impey C, Spitz AH, and Stoeger W. University of Arizona Press, Tucson, USA.

6. Peters T (2014) "Intelligent Aliens and Astroethics," in Space Exploration and ET: Who Goes There? ed., Arnould J. ATF Press, Adelaide, Australia.

7. Race MS, Randolph RO (2007) "Societal and Ethical Concerns," in Planets and Life: The Emerging Science of Astrobiology, eds., Sullivan WT, John AB. Cambridge University Press, Cambridge, UK.

8. Conley CA, John DR (2010) Planetary protection for human exploration of Mars. Acta Astronautica 66: 792-797.

9. Wickramasinghe C (2015) Evidence to Clinch the Theory of Extraterrestrial Life. Astrobiol Outreach 3: e107.

10. Hart J (2013) Cosmic Commons: Spirit, Science, and Space. Cascade Books, Eugene, OR, USA.

11. Conley CA (2014) Life Guard: an Interview with Catharine Conley. Scientific American 311: 4.

12. Wickramasinghe C, Tokoro G (2014) Life as a Cosmic Phenomenon: The Socio-Economic Control of a Scientific Paradigm. Astrobiol Outreach 2: 113.
13. Arne N (1973) The Shallow and the Deep: Long Range Ecology Movement. Inquiry 16: 95-100.

14. Holmes R (1990) "The preservation of natural value in the solar system," in Beyond Spaceship Earth: Environmental Ethics and the Solar System, ed. Hargrove EC. Sierra Club Books, San Francisco, CA, USA.

15. Richard OR (2009) "God's preferential option for life: a Christian perspective," in Exploring the Origin, Extent, and Future of Life: Philosophical, Ethical, and Theological Perspectives, ed., Bertka CM. Cambridge University Press, Cambridge, UK.

16. Deane-Drummond CE (2009) "The alpha and the omega: reflections on the origin and future of life from the perspective of Christian theology and ethics," in Exploring the Origin, Extent, and Future of Life: Philosophical, Ethical, and Theological Perspectives, ed. Bertka CM. Cambridge University Press, Cambridge, UK.

17. Persson E (2012) The Moral Status of Extraterrestrial Life. Astrobiology 12: $976-985$.

18. David A (2001) The New Uncertainty Principle. Scientific American 299:1.

19. Rummel JD, Race MS, Horneck G (2010) COSPAR Workshop on Ethical Considerations for Protection in Space Exploration. Astrobiology 12: 1017-1023.

20. Marks P (2011) Clearing the heavens, one piece at a time. New Scientist 209: 22-23.

21. Jacques A (2011) Icarus' Second Chance: The Basis and Perspectives of Space Ethics. Springer, Vienna, Austria.

22. News Report (2014) Researchers Eye Tethers for Space Debris. Science 343: 1062-1064.

23. Billings L (2015) Are We on the Cusp of War in Space? Scientific American 313: 14-18.

24. Alan SS (2013) The Low-Cost Ticket to Space. Scientific American 308: 69-73.

25. Woodruff TS (2013) "Planetocentric Ethics: Principles for Exploring a Solar System that May Contain Extraterrestrial Microbial Life," in Encountering Life in the Universe, eds., Impey C, Spitz AH, and Stoeger W. University of Arizona Press, Tucson, USA.

26. McKay CP (2013) "Astrobiology and Science: The Long View," in Encountering Life in the Universe, eds., Impey C, Spitz AH, and Stoeger W. University of Arizona Press, Tucson, USA.

27. McKay CP (2007) "Planetary ecosynthesis on Mars: restoration ecology and environmental ethics," in Exploring the Origin of Astrobiology, eds., Sullivan WT, John AB. Cambridge University Press, Cambridge, UK.

28. Cho F (2007) "An Asian Religious Perspective on Exploring the Origin, Extent and Future of Life," in Workshop Report: Philosophical, Ethical, and Theological Implications of Astrobiology, eds., Connie B, et al. Washington DC, AAAS, 208-218.

29. Crysdale CSW (2011) "God, evolution, and astrobiology," in Exploring the Origin of Astrobiology, eds., Sullivan WT, John AB. Cambridge University Press, Cambridge, UK.

30. Zubrin R (2013) Mars direct. The mars society.

31. Rojas A (2014) Islamic Leaders Issue Fatwa Prohibiting One-Way Trips to Mars. Open Minds Editorial.

32. Morin M (2013) Russian Meteor was actually a Tiny Asteroid, NASA says. Los Angeles Times.

33. Haubold HJ, Nadis S (2014) The Forgotten Remit of Astrobiology. NearEarth Objects - The United Nations International Conference: Twenty Years Later. 2: e104.

34. Nature Editorial (2013) Realities of Risk. Nature 493: 7431.

35. Gore A (2013) The Future: Six Drivers of Global Change. Random House, New York, USA. 